\title{
Effect of Rare Earth Oxide Additions on Oxidation Behavior of AISI 304L Stainless Steel
}

\author{
Marina Fuser Pillis*, Edval Gonçalves de Araújo, Lalgudi Venkataraman Ramanathan \\ Materials Science and Technology Center, Instituto de Pesquisas Energéticas e Nucleares, \\ Av. Prof. Lineu Prestes, 2242, Cidade Universitária, 05508-000 São Paulo - SP, Brazil
}

Received: February 1, 2006; Revised: October 24, 2006

\begin{abstract}
AISI 304L stainless steel powder compacts containing 2 vol\% high purity rare earth oxides were prepared by mixing the different powders in a vibratory mill followed by pressing. The compacts thus obtained were sintered in a vacuum furnace and isothermal oxidation measurements were carried out in a muffle furnace, in air, up to 200 hours at $900{ }^{\circ} \mathrm{C}$. The oxidized surfaces were examined in a scanning electron microscope and micro regions of the reaction products were studied using energy dispersive analysis. The addition of rare earth oxides decreased the oxidation rate of the stainless steel. Further evidence of predominant oxygen ion diffusion controlling the overall oxidation process in rare earth containing chromium oxide forming alloys has been observed.
\end{abstract}

Keywords: rare earth elements, oxidation, high temperature

\section{Introduction}

Alloys for use at high temperatures should have adequate mechanical strength and resistance to chemical degradation caused by reactions between the alloy and the environment ${ }^{1,2}$. Most structural alloys are $\mathrm{Fe}, \mathrm{Ni}$ or Co based alloys and the oxides formed on their surfaces are not sufficiently protective above $550^{\circ} \mathrm{C}$. Therefore these alloys contain $\mathrm{Cr}$ and/or $\mathrm{Al}$ to form more protective oxide scales of chromium oxide or alumina respectively ${ }^{3}$. The addition of other reactive elements such as yttrium, zirconium or cerium, to these alloys improves the protective properties of the surface oxides even more ${ }^{4-8}$. Rare earth (RE) oxides in the form of dispersions have also been added to these alloys to form protective surface oxides ${ }^{9}$. Various mechanisms have been proposed to explain the improvements in oxidation resistance brought about by addition of RE elements or their oxides. The mechanism most widely accepted attributes the improvements to diffusion of the RE ions to oxide grain boundaries and blocking of alloy cation diffusion from the metal/oxide to the oxide/air interface ${ }^{10}$. This paper presents the effect of neodymium, yttrium, lanthanum and ytterbium oxide additions on oxidation behavior of AISI 304L stainless steel.

\section{Materials and Methods}

Powders of AISI 304L (0.01 C, 0.01 S, $11.3 \mathrm{Ni}, 19.1 \mathrm{Cr}, 0.9 \mathrm{Si}$, $0.159 \mathrm{O}, 0.056 \mathrm{~N}, 0.2 \mathrm{Mn}$ and balance $\mathrm{Fe}$ ) and 2 vol.\% high purity oxides of neodymium, ytterbium, lanthanum and yttrium were mixed for 1 hour in a vibratory mill to obtain the powder mix. This powder mix was compacted in a uniaxial press and the compacts sintered in vacuum for 1 hour at $1250{ }^{\circ} \mathrm{C}$. Specimens of the compacts for optical microscopy were polished and etched by immersion for 5 seconds in a solution containing $30 \mathrm{~mL}$ hydrochloric acid and $20 \mathrm{~mL}$ ethanol. Isothermal oxidation was carried out in a muffle furnace for 200 hours at $900{ }^{\circ} \mathrm{C}$. Weight gains vs. time curves were obtained and the weight gains took into account the weight of the spalled oxide, where pertinent. The surfaces and cross sections of specimens oxidized for 20 hours and 200 hours were examined in a scanning electron microscope and energy dispersive spectroscopic analysis of micro-regions carried out.

*e-mail: mfpillis@ipen.br

Article presented at the $4^{\text {th }}$ International Latin-american conference on Powder

Technology, November 19-21, Guarujá, São Paulo, 2003, Brazil

\section{Results and Discussion}

The hydrostatic density of the various sintered materials did not vary much and was in the range 86.2 to $89.1 \%$ of the theoretical density.

Figure 1 shows micrographs of longitudinal sections of sintered AISI 304L. Neck formation between alloy particles and irregular shaped pores can be seen in Figure 1a. Twinned austenite grains are shown in Figure 1b. The cross-section and longitudinal section of the $\mathrm{Yb}_{2} \mathrm{O}_{3}$ containing specimen are shown in Figure $2 \mathrm{a}$ and $\mathrm{b}$. Embedded $\mathrm{RE}$ oxide particles at metal particle interfaces(arrows) and twinned austenite grains can be observed.

The weight gain $v s$. time curves of specimens oxidized in the muffle furnace are shown in Figure 3. Addition of RE oxides decreased the overall weight gain compared to the stainless steel without any additions. After 20 hours at $900{ }^{\circ} \mathrm{C}$, none of the specimens spalled. After 50 hours, among all the samples, only the oxides on specimens without $\mathrm{RE}$ additions and with $\mathrm{Y}_{2} \mathrm{O}_{3}$ started spalling. Oxide spalling on $\mathrm{Y}_{2} \mathrm{O}_{3}$ containing specimen was slight and in the form of a fine powder, where as that on the specimen without additions of RE oxides was in the form of large scales. During the first 20 hours of oxidation, the effect of adding the different RE oxides was similar.

Figure 4a shows the surface of AISI 304L oxidized for 20 hours. Acicular oxides can be seen in region 1 and this was rich in $\mathrm{Fe}$ and $\mathrm{Ni}$. Region 2 was rich in $\mathrm{Fe}$ and contained traces of $\mathrm{Cr}$ and $\mathrm{Ni}$. A cross-section of the same material is shown in Figure $4 \mathrm{~b}$ and an irregular oxide layer is seen. The oxide/metal interface is undulating and regions with internal oxidation can also be observed besides cracks and pores. The outer part of the oxide layer (region 1) consists essentially of $\mathrm{Fe}$ and some $\mathrm{Cr}$. In the lighter intermediate region (region 2), Ni was also observed. The internal oxidation zone (region 3) revealed $\mathrm{Cr}$ and $\mathrm{Ni}$, and region 4, close to the metal/oxide interface was rich in $\mathrm{Cr}$.

The surface of AISI 304L oxidized for 200 hours is shown in Figure 5a. The specimens revealed severe spalling. Oxides with varying morphologies can be observed. EDS analysis revealed that in spite of the differing morphologies, they were all rich in Fe. In the oxides shown with numbers 1 and 2, small quantities of $\mathrm{Cr}$ was detected, and in the oxide shown with number 3 , besides $\mathrm{Fe}$ and $\mathrm{Cr}$, $\mathrm{Ni}$ was also present. Figure $5 \mathrm{~b}$ shows a region of the oxide that was still adhering 


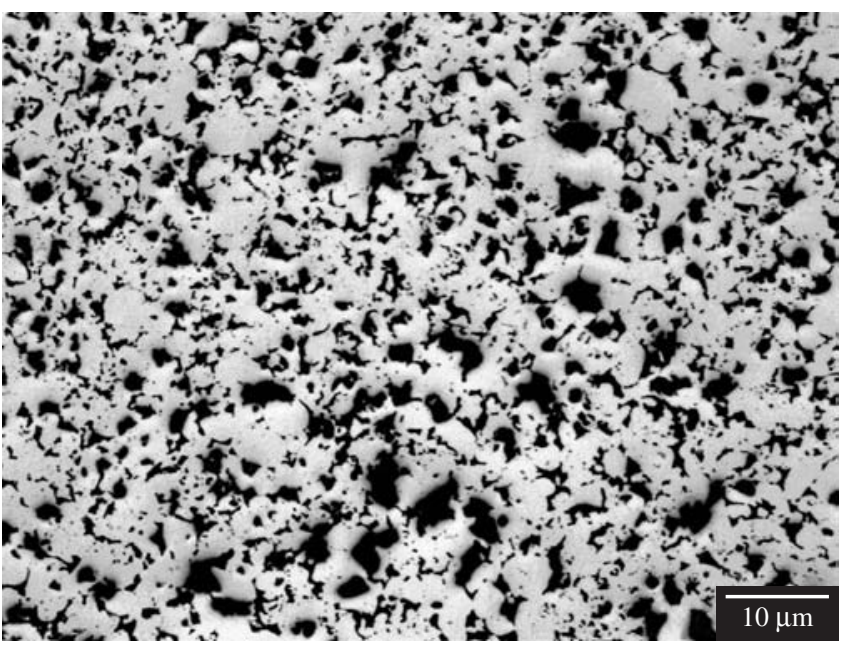

(a)

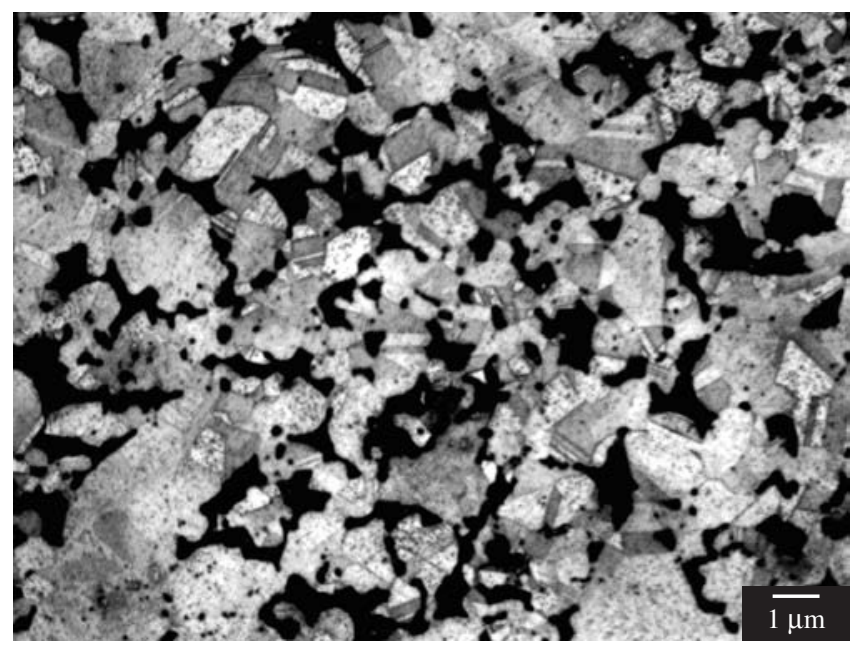

(b)

Figure 1. Longitudinal sections of sintered AISI 304L. a) not etched; and b) etched.

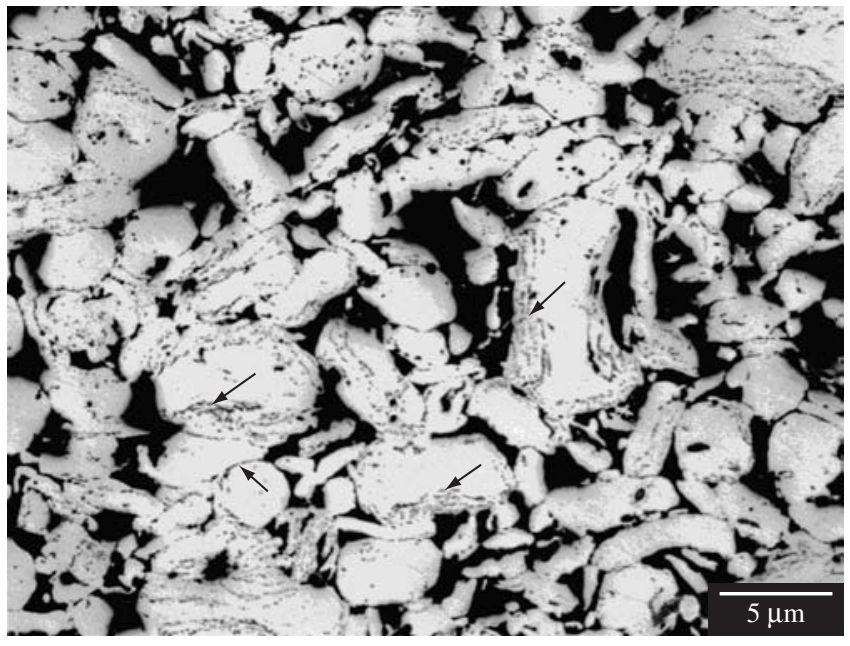

(a)

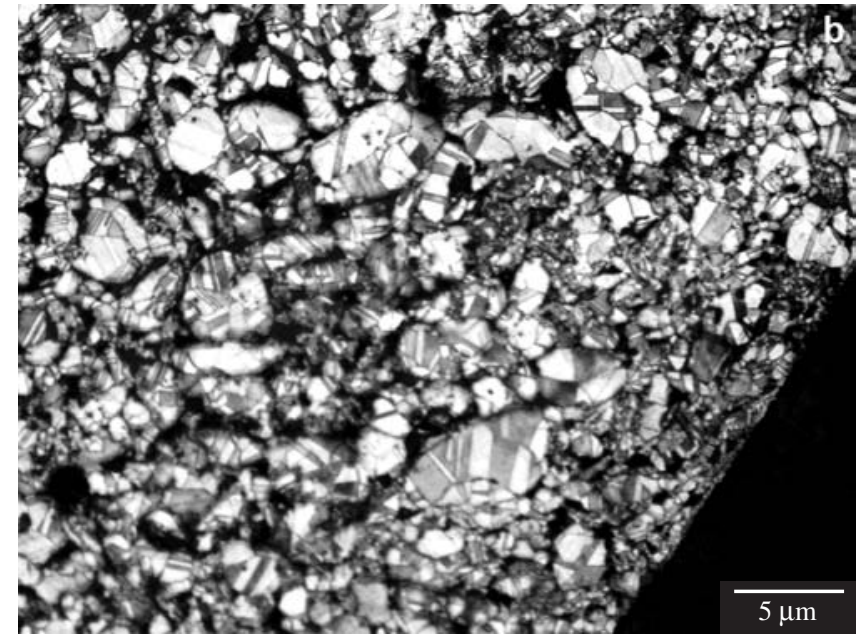

(b)

Figure 2. Microstructure of sintered AISI 304L $+\mathrm{Yb}_{2} \mathrm{O}_{3}$. a) cross-section without etching; and b) longitudinal section etched.

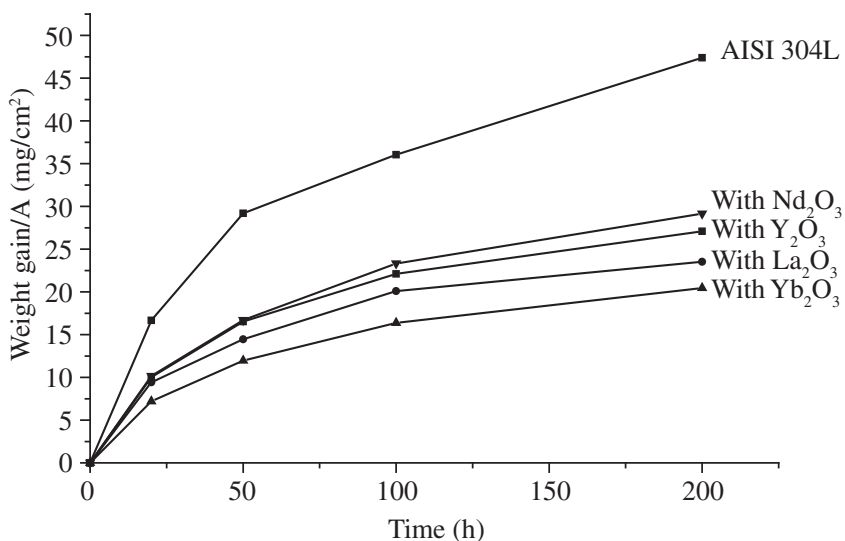

Figure 3. Oxidation Curves at $900{ }^{\circ} \mathrm{C}$.

to the alloy and revealed high $\mathrm{Cr}$ content. The cross section of the same material is shown in Figure 5c and high Fe with traces of $\mathrm{Cr}$ was noted in region 1 and high $\mathrm{Ni}$ in region 2 . Figure $5 \mathrm{~d}$ is a higher magnification micrograph of a part of the oxide still adhering to the base metal and it reveals zones of internal oxidation. Region 1 was found to be rich in $\mathrm{Cr}$ and $\mathrm{Fe}$, region 2 contained high $\mathrm{Ni}$ besides $\mathrm{Cr}$ and $\mathrm{Fe}$ and region 3, revealed large amounts of $\mathrm{Cr}$ and $\mathrm{Fe}$.

Figure 6a presents the surface of $\mathrm{Yb}_{2} \mathrm{O}_{3}$ containing AISI304L oxidized for 20 hours. The light colored regions are $\mathrm{Yb}_{2} \mathrm{O}_{3}$. The morphology of the oxide formed on the surface is quite distinct from that formed on the RE oxide free steel (Figure 4a). Figure $6 \mathrm{~b}$ is a cross section of the same material and reveals an oxide layer that is thinner than that formed on RE oxide free steel. Pores can also be observed in the oxide. The light regions within the oxide layer were identified as $\mathrm{Yb}_{2} \mathrm{O}_{3}$ particles and serve as a marker, indicating the oxide growth direction, that is, towards the alloy. This lends further proof to oxide growth mechanism in the presence of RE being by anion diffusion. On the outer regions of the oxide, close to the oxide/gas interface, indicated in the micrograph as $1, \mathrm{Cr}$ and $\mathrm{Ni}$ were detected, besides $\mathrm{Fe}$. In the intermediate lighter region 2 , the $\mathrm{Ni}$ level was higher and in region 3, close to the oxide/metal interface, the $\mathrm{Cr}$ level was high. Region 4 is a $\mathrm{Yb}_{2} \mathrm{O}_{3}$ agglomerate.

The surface and cross section of AISI 304L $+\mathrm{Yb}_{2} \mathrm{O}_{3}$ oxidized for 200 hours are shown in Figures $7 \mathrm{a}$ and $7 \mathrm{~b}$. Region 1, close to the oxide/gas interface showed only $\mathrm{Fe}$ and region 2, large amounts of $\mathrm{Ni}$ and $\mathrm{Cr}$, besides $\mathrm{Fe}$. The intermediate light region 3, was rich in $\mathrm{Ni}$ 


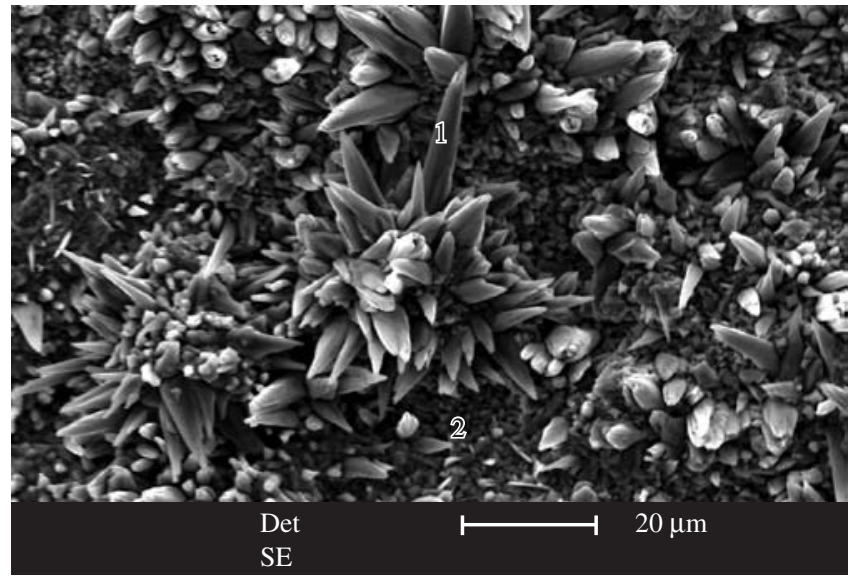

(a)

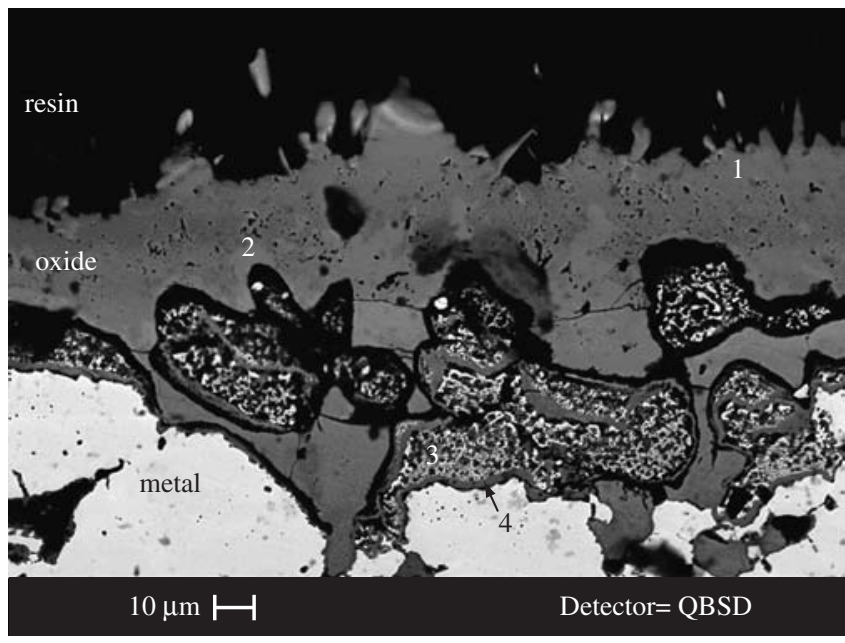

(b)

Figure 4. AISI 304L oxidized for 20 hours at $900{ }^{\circ} \mathrm{C}$. a) surface; b) cross-section.

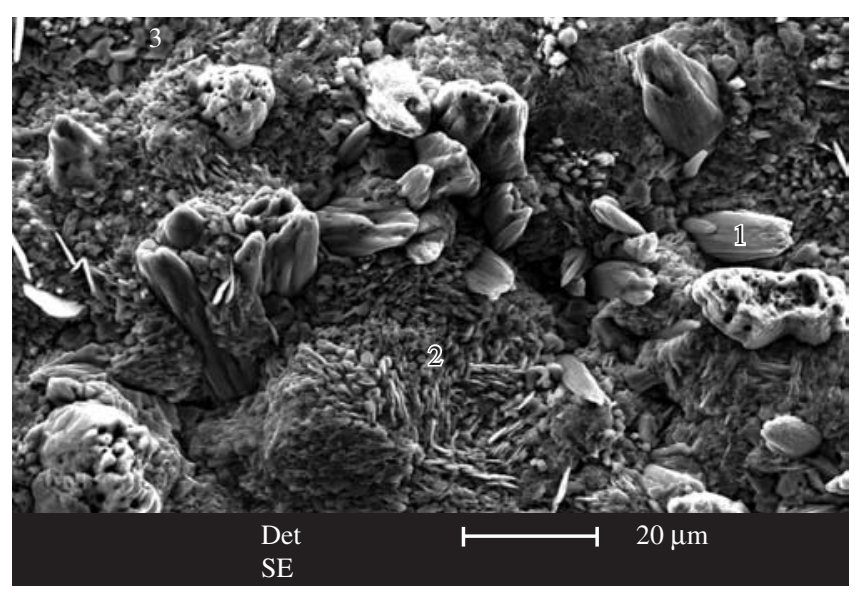

(a)

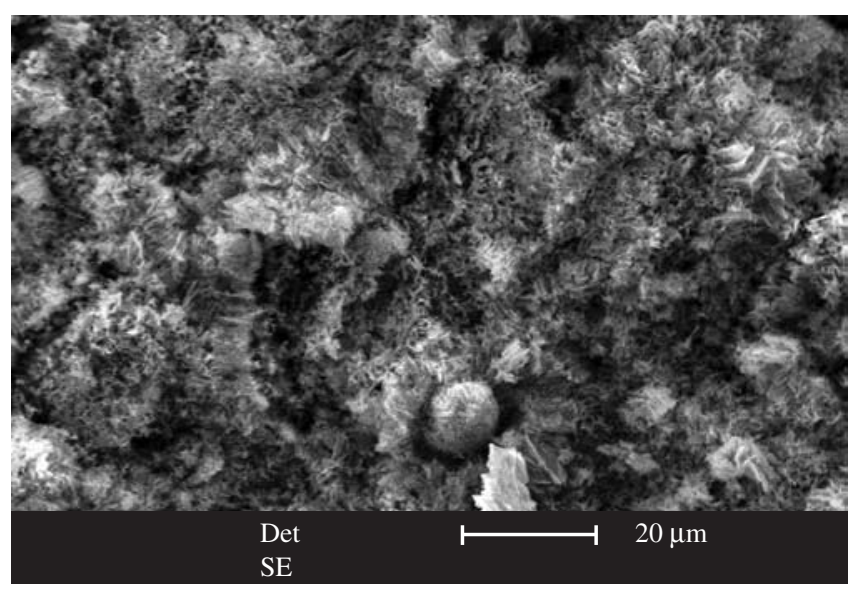

(b)

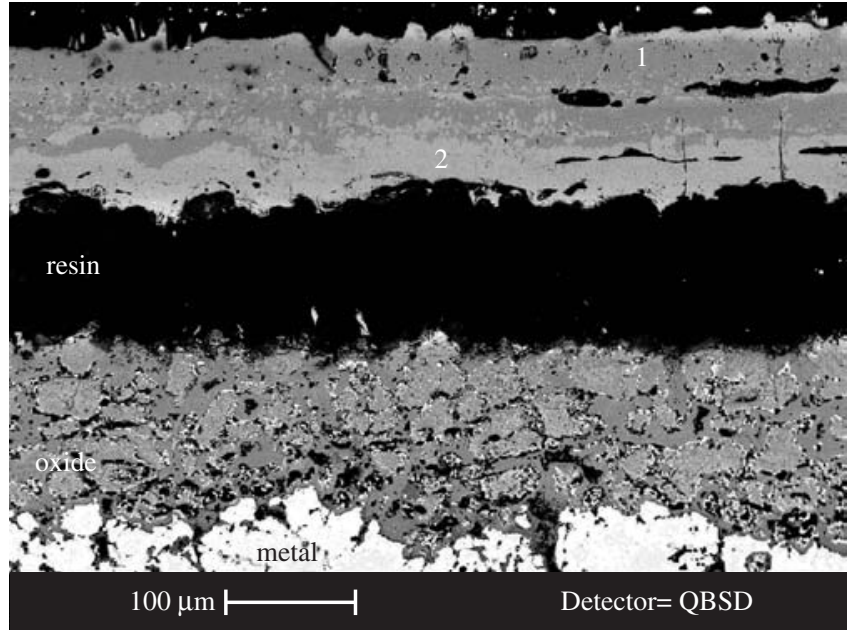

(c)

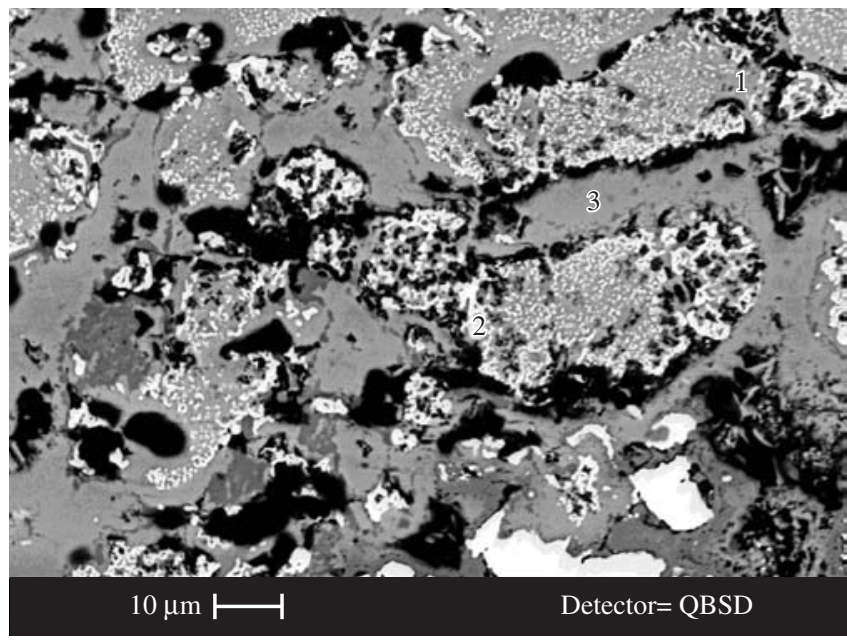

(d)

Figure 5. AISI $304 \mathrm{~L}$ oxidized for 200 hours at $900{ }^{\circ} \mathrm{C}$. a) surface (not spalled region); b) surface (spalled region); c) cross-section; and d) higher magnification in a region of (c). 


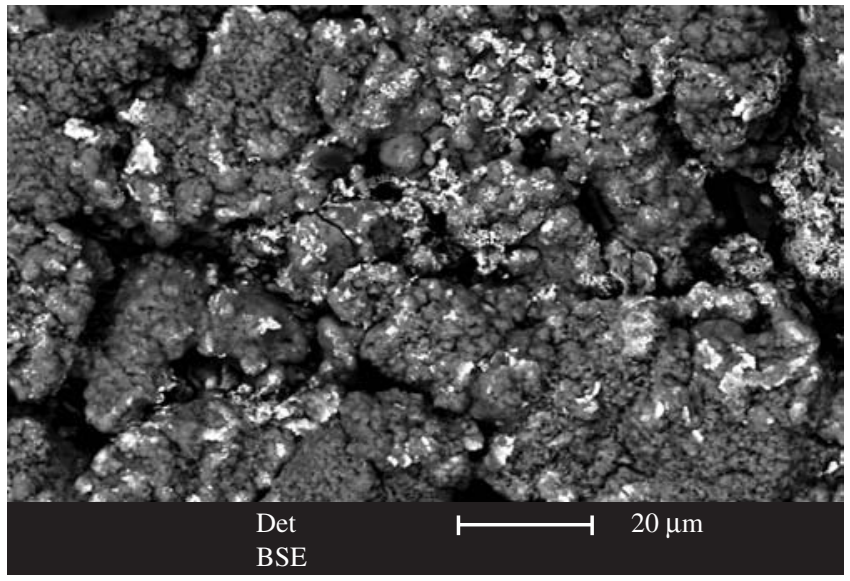

(a)

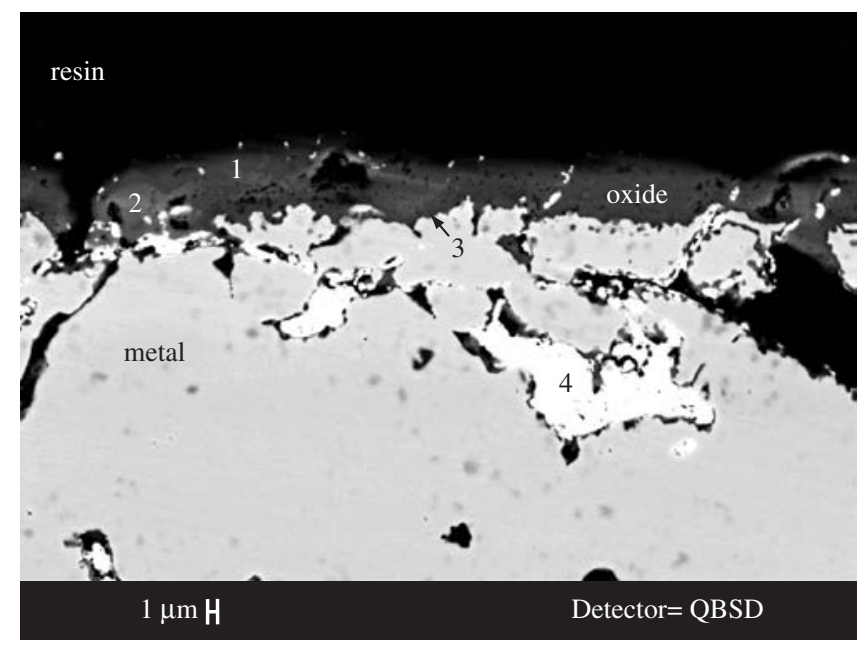

(b)

Figure 6. AISI $304 \mathrm{~L}+\mathrm{Yb}_{2} \mathrm{O}_{3}$ oxidized for 20 hours at $900{ }^{\circ} \mathrm{C}$. a) surface; and b) cross-section.

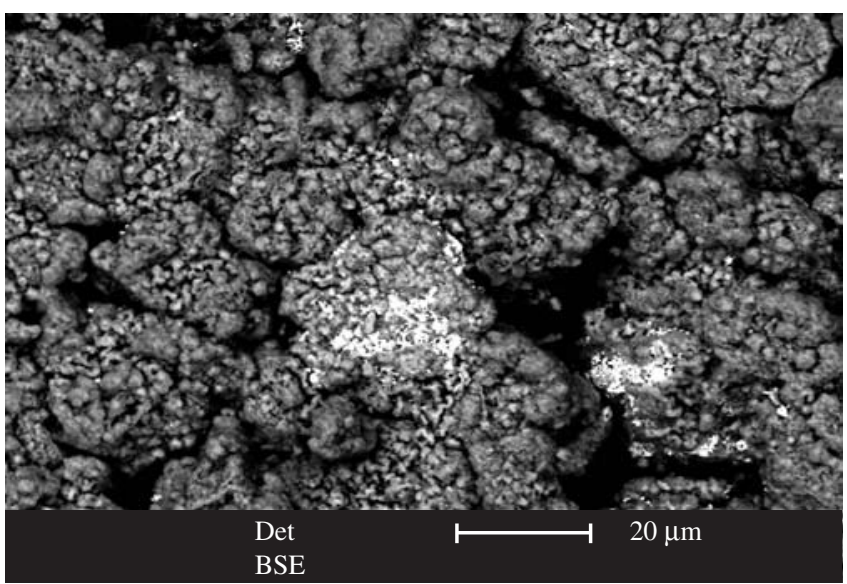

(a)

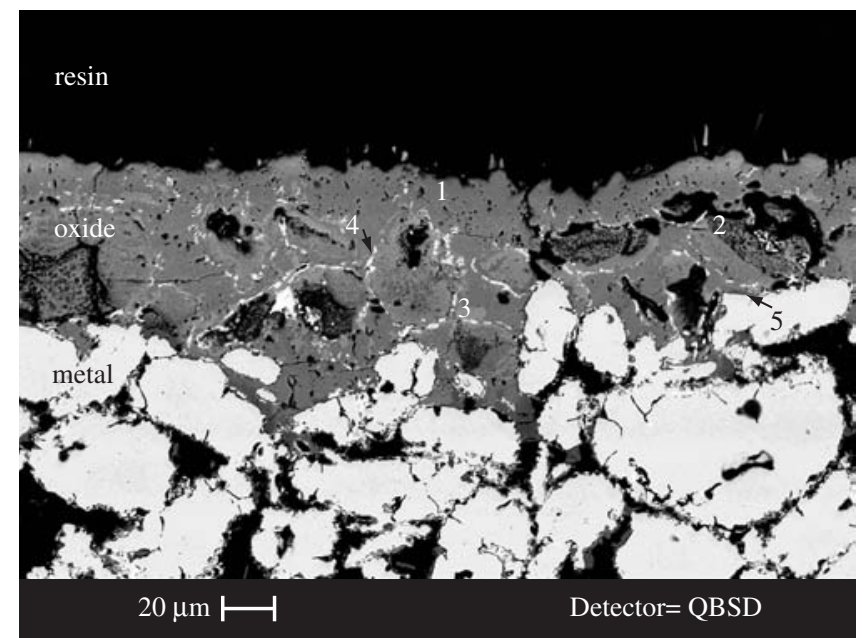

(b)

Figure 7. AISI $304 \mathrm{~L}+\mathrm{Yb}_{2} \mathrm{O}_{3}$ oxidized for 200 hours at $900{ }^{\circ} \mathrm{C}$. a) surface; and b) cross-section.

and region 4 is a particle of $\mathrm{Yb}_{2} \mathrm{O}_{3}$ present at alloy particle boundaries. Region 5, close to the oxide/metal interface is rich in $\mathrm{Cr}$.

Similar microstructures were observed in the case of the other RE oxide dispersion containing steels. The mechanism most widely accepted at present, among those that have been put forth ${ }^{3,10-19}$, to explain the reactive element effect, especially in so far as its effect on chromia growth, is the change in the ion species that diffuses predominantly. In rare earth free $\mathrm{FeCr}$ alloys, chromia growth takes place as a result of diffusion, of both oxygen and chromium ${ }^{19}$, along grain boundaries, and the oxide layer is thick. On the other hand, in $\mathrm{RE}$ containing $\mathrm{FeCr}$ alloys, chromia growth is due to predominant oxygen ion diffusion ${ }^{10}$. The oxide layer is thin and plastic. Consequently the oxide layer is more adherent. The rare earth ions segregate to grain boundaries in the alloy and the oxide, close to the metal/oxide interface or to grain boundaries of the oxide. The ionic radii of the rare earths are significantly higher than that of the elements in the steel, $\mathrm{Fe}$ and $\mathrm{Cr}$, and their presence at the alloy or oxide grain boundaries impedes cation diffusion. This in turn transforms regular anion diffusion into the predominant diffusing species and thus determines oxide growth.

\section{Conclusions}

Rare earth oxide additions to AISI 304L stainless steels decreased overall weight gain due to oxidation. The influence of RE additions on oxidation behavior remained effective for up to 200 hours. The results of microscopic examination of oxidized surfaces and sections gave further evidence that oxide growth on RE containing steels was by predominant oxygen diffusion.

\section{Ackowlegments}

The Authors wish to thank FAPESP for the financial support given through Project $N^{\circ}$ 01/13748-6.

\section{References}

1. Sttot FH. Influence of alloy additions on oxidation. Materials Science and Technology. 1989; 5:734.

2. Pettit FS, Goward GW. High temperature corrosion and use of coatings for protection. In: Superalloys source book, ASM. 1981. p. 170-186. 
3. Hou PY, Stringer J. The effect of surface-applied reactive metal oxides on the high temperature oxidation of alloys. Materials Science and Engineering. 1987; 87:295.

4. Pillis MF, Ramanathan LV. Effect of Processing Technique on Microstructure and Oxidation Behavior of Rare Earth Oxide Dispersion Containing Steels. Key Engineering Materials. 2001; 189-191:322.

5. Pillis MF, Ramanathan LV. Effect of alloying additions and preoxidation on high temperature sulphidation resistance of iron-chromium alloys. Surface Engineering. 2006; 22(2):129.

6. Brossard J-M, Balmain J, Cresus J, Bonnet G. Characterization of thin solid films containing yttrium formed by electrogeneration of base for high temperature corrosion applications. Surface and Coatings Technology. 2004; 185:275.

7. Zhu L, Peng X, Yan J, Wang F. Oxidation of a Novel Chromium Coating with $\mathrm{CeO}_{2}$ Dispersions. Oxidation of Metals. 2004; 62(5/6):411.

8. Chevalier S, Bonnet G, Larpin JP. Metal-organic chemical vapour deposition of $\mathrm{Cr}_{2} \mathrm{O}_{3}$ and $\mathrm{Nd}_{2} \mathrm{O}_{3}$ coatings. Oxide growth kinetics and characterization. Applied Surface Science. 2000; 167:125.

9. Pillis MF, de Araújo EG, Ramanathan LV. Effect of Addition of Rare Earth Oxide Concentrates on Oxidation Behavior of AISI 304L Stainless Steel. TMS Letters; 2004. p. 57.

10. Jedlinski J, Mrowec $S$. The influence of implanted yttrium on the oxidation behavior of -Ni-Al. Materials Science and Engineering. 1987; 87:281.
11. Rhys-Jones TN, Grabke HJ, Kudielka H. The effects of various amounts of alloyed cerium and cerium oxide on the high temperature oxidation of $\mathrm{Fe}-10 \mathrm{Cr}$ and $\mathrm{Fe}-20 \mathrm{Cr}$ alloys. Corrosion Science. 1987; 27(1):49.

12. Moon DP. Role of reactive elements in alloy protection. Materials Science and Technology. 1989; 5:754.

13. Cotell CM, Yurek GJ, Hussey RJ, Mitchell DF, Graham MJ. The influence of grain-boundary segregation of $\mathrm{Y}$ in $\mathrm{Cr}_{2} \mathrm{O}_{3}$ on the oxidation of $\mathrm{Cr}$ metal. Oxidation of Metals. 1990; 34(3/4):173.

14. Whittle DP, Stringer J. Improvements in high temperature oxidation resistance by additions of reactive elements or oxide dispersions. Philosophical. Transactions of the Royal Society of London. 1980; A295:309.

15. Pieraggi B, Rapp RA. Chromia scale growth in alloy oxidation and the reactive element effect. Journal of the Electrochemical Society. 1993; 140(10):2844.

16. Rhys-Jones TN, Grabke HJ. Use of cerium and cerium oxide additions to improve high temperature oxidation behaviour of $\mathrm{Fe}-\mathrm{Cr}$ alloys. Materials Science and Technology. 1988; 4:446.

17. Pilling NB, Bedworth RE. The oxidation of metals at high temperatures. Journal of the Institute of Metals. 1923; 29:529.

18. Yurek GJ. Mechanisms of diffusion-controlled high-temperature oxidtion of metals. In: Corrosion Mechanisms. revised ed. New York: Marcel Dekker; 1987. p. 397-446.

19. Banovic SW, Dupont JN, Marder AR. High temperature sulfidation behavior of low Al iron-aluminium compositions. Scripta Materialia. 1998; 38(12): 1763 
